\title{
Correction to: ALORA: Affine Low-Rank Approximations
}

\author{
Alan Ayala $^{1}$ (D) Xavier Claeys $^{2} \cdot$ Laura Grigori $^{1}$ \\ Published online: 14 February 2019 \\ ๑) Springer Science+Business Media, LLC, part of Springer Nature 2019
}

\section{Correction to: Journal of Scientific Computing https://doi.org/10.1007/s10915-018-0885-5}

The original version of the article contained a mistake in Acknowledgement section. The corrected text is given below:

Acknowledgements The authors' work was supported by the NLAFET project as part of European Union's Horizon 2020 research and innovation program under Grant 671633. XC acknowledges support of the French National Research Agency (ANR) Contract ANR-15-CE23-0017-01 (project NonlocalDD).

Publisher's Note Springer Nature remains neutral with regard to jurisdictional claims in published maps and institutional affiliations.

The original article can be found online at https://doi.org/10.1007/s10915-018-0885-5.

$凶$ Alan Ayala

alan.ayala-obregon@inria.fr

Xavier Claeys

claeys@ann.jussieu.fr

Laura Grigori

laura.grigori@inria.fr

1 Laboratoire Jacques-Louis Lions, INRIA Paris, Sorbonne Université, Univ Paris-Diderot SPC, CNRS, équipe ALPINES, Paris, France

2 Laboratoire Jacques-Louis Lions, Sorbonne Université, Univ Paris-Diderot SPC, CNRS, INRIA, équipe ALPINES, 75005 Pairs, France 